\title{
Cardiorespiratory response to exercise of nonsmokers occupationally exposed to second hand smoke (SHS)
}

\author{
Anastosios Mantzoros ${ }^{1}$, Stephanie Irene Teloniatis ${ }^{2}$, Mario Lymperi' ${ }^{1}$, Anno Tzortzi ${ }^{2,3}$, Panagiotis Behrakis ${ }^{2,3}$
}

\begin{abstract}
INTRODUction Occupational exposure to Second Hand Smoke (SHS) continues to be an issue, even in countries with strong tobacco control legislation. The current study assessed the effect of chronic occupational exposure to SHS on cardiorespiratory exercise response among healthy adult non-smokers.

METHODS 60 healthy non-smokers; 38 men, 22 women, aged 18-58 years with body mass index $(B M I)<30$ were separated into exposed to occupational SHS (exposed, $n=30$ ) and those non-exposed (controls, $\mathrm{n}=30$ ) to occupational SHS in the hospitality sector. All individuals underwent baseline spirometry and ergospirometry testing. Non-smoking status was confirmed with exhaled CO, SHS exposure with urine cotinine measurement and indoor environmental pollution with PM2.5 concentration. Statistical differences among groups were determined with an independent t-test and p-value set to $<0.05$.

RESULTS The exposed group had an average range of $6.9 \%$ to $14 \%$ lower exercise performance against their \% predicted compared to controls. Significant mean differences \pm standard deviation found between groups for ergospirometry were: oxygen uptake $\left(\mathrm{VO}_{2}, \mathrm{~mL} / \mathrm{minute}\right) 11.8 \pm$ $3.9(\mathrm{p}=0.004)$ and $11.7 \pm 4.8(\mathrm{p}=0.019)$; carbon dioxide output $\left(\mathrm{VCO}_{2}\right) 14.0 \pm 3.7(\mathrm{p}<0.001)$ and $13.4 \pm 5.0(\mathrm{p}=0.009)$; metabolic equivalents (METS) $11.9 \pm 3.9(\mathrm{p}=0.003)$ and $11.7 \pm 4.9$ $(\mathrm{p}=0.018)$ and for oxygen pulse $\left(\mathrm{VO}_{2} / \mathrm{HR}\right) 16.6 \pm 7.551(\mathrm{p}=0.032)$ and $11.9 \pm 4.554(\mathrm{p}=0.011)$ at points of maximum oxygen uptake $\left(\mathrm{VO}_{2} \max \right)$ and recovery $(\mathrm{RC})$ against \% predicted values, respectively.

concLusion Chronic occupational SHS exposure among non-smokers deteriorates CR exercise performance. Its impact on chronic disease development should be further explored. These results add to the evidence of the importance of enforcing clean indoor air legislations..
\end{abstract}

\section{AFFILIATION}

1 National and Kapodistrian University of Athens, Faculty of Medicine, Athens, Greece 2 George D. Behrakis RESEARCH LAB - Hellenic Cancer Society, Athens, Greece 3 Institute of Public Health -The American College of Greece, Athens, Greece

\section{CORRESPONDENCE TO}

Stephanie Irene Teloniatis, George D. Behrakis RESEARCH LAB -Hellenic Concer Society. Dorileou 8, 11521 Athens, Greece.

Email:steloniatis@gmail.com

\section{KEYWORDS}

passive smoking, exercise test, cardiovascular, oxygen uptake, PM2.5, occupational health
LIST OF ABBREVIATIONS

Secondhand Smoke (SHS) Cardiovascular Diseases (CVD)

Chronic Obstructive Pulmonary Disease (COPD)

Sudden infant death syndrome (SIDS)

Cardiovascular (CV)

Cardiorespiratory (CR)

Over-the-counter (OTC)

Body mass index (BMI)

European Respiratory Society-

American

Thoracic Society

(ERS-ATS)

Forced vital capacity (FVC)

Forced expiratory volume

in the first second (FEVI)

Tiffeneau index (FEVI/FVC)
Mid-expiratory flow (FEF)

Heart rate (HR)

Exercise flow-volume

Ioop (ExFVL)

Oxygen uptake $\left(\mathrm{VO}_{2}\right)$

Carbon dioxide output $\left(\mathrm{VO}_{2}\right)$

Ventilation (VE)

Respiratory quotient (RQ)

Ventilatory equivalent ratio for

oxygen uptake (VE/ $\mathrm{VO}_{2}$ )

Carbon dioxide output

(VE/ $\mathrm{VO}_{2}$ )

Metabolic equivalents (METS)

Anaerobic threshold (AT)

Particulate matter (PM2.5)

Maximum heart rate (HRmax)

Recovery (RC)

Oxygen pulse $\left(\mathrm{VO}_{2} / \mathrm{HR}\right)$

\section{INTRODUCTION}

Secondhand smoke (SHS) was first reported as a danger to non-smokers by Hirayama and Trichopoulos et al. in 1981, who found increased risk for developing lung cancer among non-smoking women married to smokers ${ }^{12}$. Since then, scientific evidence has repeatedly associated exposure to SHS with disease and premature death in adults and children ${ }^{3}$. In adults, SHS has been associated with cardiovascular diseases (CVD), stroke, lung cancer, chronic obstructive pulmonary disease (COPD), asthma exacerbation and reproductive effects in women such as low birth weight infants ${ }^{4,5}$. Children exposed to SHS are particularly vulnerable, being put at risk for developing rhinitis, eye irritation, middle ear 
infection, increased respiratory symptoms such as cough, chest discomfort, wheezing, lower respiratory infections and sudden infant death syndrome ${ }^{6,7}$.

Smoking is known to adversely affect the cardiovascular (CV) system and exercise performance ${ }^{4}$ and SHS exposure is also associated with increased $\mathrm{CV}$ risk $^{8-11}$. Studies on occupational exposure of SHS and the effect on nonsmokers' cardiorespiratory (CR) response to exercise testing are limited. Both McMurray et al. who studied a group of 8 women by smoking status, with and without SHS exposure using simulated smoke during exercise testing ${ }^{12}$ and Flouris et al. who studied SHS exposure using self-burning cigarettes to simulate bar-level exposure among healthy non-smoking adults via exercise testing ${ }^{7}$, measured short-term exposure effect of SHS on the CR system. A study by Thier de Borba et al. measured CR response through sub-maximal exertion incremental testing on a treadmill in the general population separated by smoking status ${ }^{13}$. In 2009, Arjomandi et al. studied occupational exposure to SHS in flight cabins among non-smoking flight attendants prior to implementation of commercial smoking bans and examined their flow-volume curves, diffusion capacity and lung volumes ${ }^{6}$.

Preventive policies for tobacco control include banning smoking indoors in public places and have been embraced by many countries but leave an estimated $84 \%$ of the population unprotected ${ }^{14}$. Unfortunately, even with adopted legislation, many countries have not managed to enforce the bans as is the current case in Greece ${ }^{15}$, while in others, have failed to include coverage of hospitality venues ${ }^{16}$. Individuals working in environments polluted with SHS such as hospitality venues are therefore exposed to SHS daily and chronically, highlighting the importance of examining the effect of longterm exposure on CR health.

The health effects of SHS, the fact that decreased CR response is linked to higher mortality rates in comparison to normal responses ${ }^{13}$ and the fact that many workers are still unprotected from clean indoor air legislation drive the need to further investigate the effect of long-term occupational SHS exposure on CR exercise performance.

Therefore, the current study aimed to further examine the CR response to exercise testing among healthy adult nonsmokers exposed to occupational SHS and compare them to those not occupationally exposed to SHS.

\section{METHODS}

\section{Somple population}

The study recruited subjects from three Greek towns of Amfissa, Itea and Desfina in the Phocis region through open advertisement and word-of-mouth. Inclusion criteria included being age 18+ years of age, insignificant medical history, no prescribed or over-the-counter medications, non-smoker (including tobacco, nicotine products, or novel devices), and body mass index $(\mathrm{BMI})<30$. Exclusion criteria included being $<18$ years of age, pregnancy or lactation, presence of any chronic or acute disease or infection (<than 4 weeks prior to study) or taking any medications $(<4 \text { weeks })^{17}$. Each participant was informed of the purpose and scope of the study in detail and provided their written informed consent in accordance with Article 8, N.1599/1986 prior to beginning of the study, that was implemented following the ethical guidelines outlined by the doctorate degree program at the University of Athens Medical School.

Subjects were separated into exposed to SHS (exposed) and non-exposed to SHS (control) groups according to occupational exposure. Exposed participants were defined as those occupationally exposed to SHS for a minimum of 8 hours per day and ultimately consisted of staff that worked in cafes and bars. Those in the control group worked in public places such as schools, gyms and offices where smoking is strictly prohibited. All participants first completed a questionnaire collecting demographic, anthropometric, health and smoking history and SHS exposure information.

\section{Equipment and Lung function tests}

An ULTIMA CPX-006 system of Medical Graphics was used to measure CR parameters and gas exchange through high sensitivity gas and flow sensors in accordance with European Respiratory Society-American Thoracic Society (ERS-ATS) recommendations ${ }^{18}$ and were calibrated as per manufacturer's protocol prior to each test. Each participant was informed of the procedure and tested at least two hours outside of work shift and at least three hours post-prandial. A physician was present during all testing.

Baseline spirometry was performed in resting conditions prior to the ergospirometry test. Variables evaluated for baseline spirometry were forced vital capacity (FVC), forced expiratory volume in the first second (FEV1), Tiffeneau index (FEV1/FVC) and mid- expiratory flow (FEF-75\%) ${ }^{19}$.

Ergospirometry was performed using the Bruce 10\% protocol (treadmill, incremental grade and speed; 7 stages of 3 minute durations including warm-up). Flow-volume loops and inspiratory capacity were performed at the beginning and end of all stages ${ }^{20}$. Each participant began the test by having a trial walk test on the treadmill and was closely monitored at all times. Masks were carefully fitted for each patient. A breath-by-breath respiratory gas analysis was continuously 
monitored and recorded along with heart rate (HR). Following the protocol, the subject was given a 3-minute recovery period and was able to interrupt the protocol at any point.

Variables evaluated were grade $(\%)$, speed $(\mathrm{km} / \mathrm{hr})$, heart rate (HR), exercise flow-volume loop (ExFVL), oxygen uptake $\left(\mathrm{VO}_{2}\right.$ in $\mathrm{mL} / \mathrm{kg} / \mathrm{min}$ and $\mathrm{mL} / \mathrm{min}$ ), carbon dioxide output $\left(\mathrm{VCO}_{2}, \mathrm{~mL} / \mathrm{min}\right), \mathrm{VO}_{2} \max$, anaerobic threshold (AT), ventilation ( $\mathrm{VE}, \mathrm{L} / \mathrm{min}$ ), respiratory quotient (RQ), ventilatory equivalent ratio for oxygen uptake (VE/ $\mathrm{VO}_{2}$ ) and for carbon dioxide output (VE/ $\mathrm{VCO}_{2}$ ), WorkAT, WorkMAX and metabolic equivalents (METS). $\mathrm{VO}_{2} \max$ was defined as the point of maximum value of oxygen uptake achieved toward the end of the test. AT was estimated using V-slope method ${ }^{21}$. Maximum heart rate (HRmax) was defined as the time point at which the highest HR was reached during the test. Parameters were calculated by the system's software using Harris-Benedict protocol $^{22}$ and Wasserman equations ${ }^{21}$.

\section{Exhaled CO, Urine cotinine and PM2.5 measurements}

Non-smoking status of participants was confirmed by exhaled CO measurements taken using a Bedfont piCO Smokerlyzer ${ }^{23}$ and calibrated according to manufacturer guidelines. Values measured $<7 \mathrm{ppm}$ were considered non-smokers ${ }^{24}$. Urine cotinine was used as the biomarker to confirm exposure to SHS in the sample population ${ }^{25-28}$. Morning urine was collected for each participant and measured using a DRG diagnostics $\mathrm{kit}^{29}$. PM2.5 measurements were conducted during winter months as bars and cafes keep doors and windows closed and exposure to SHS is maximized. The tests were made in all workplaces using a SidePAK TSI Personal Aerosol Monitor, calibrated from the manufacturer. The measurements were taken over a minimum of 10-minute intervals in each location to reflect momentary values during peak business hours (11AM-2PM and 7PM-10PM). Exposed workplaces did not have operating kitchens, burning candles or fireplaces ${ }^{30}$ therefore excluding the possibility of competing influence of PM2.5 exposure from other smoke byproducts.

\section{Statistical Analysis}

IBM SPSS statistics software version 22.0 was used for statistical analysis. Normality of distribution was determined using Shapiro-Wilks test and equality of variances with Levene's test. Descriptive statistics of the control and exposed groups were summarized for demographic characteristics, spirometry, ergospirometry, urine cotinine concentrations and PM2.5. A correlation analysis using Spearman RHO test was used for all variables by age, height, weight and BMI. Reference time points Rest, $\mathrm{AT}, \mathrm{VO}_{2}$ max and Recovery (RC) were used for ergospirometry analysis between groups. An independent t-test determined significant differences between control and exposed groups' with a significance level set to p-value $<0.05$.

\section{RESULTS}

\section{Summary Statistics}

The total sample of 60 participants consisted of two groups (control and exposed) of 30 participants. The control group was evenly distributed by gender with a majority having an education of high school or above. The exposed group had more men and a majority who had a high school or university education. The control group had similar BMI average to the exposed group (Table 1).

\section{Exhaled CO, Urine Cotinine and PM2.5}

Exhaled CO measurements of all 60 participants were $<7 \mathrm{ppm}$ confirming their non-smoking status. Mean urine cotinine level in the control group was $518.8 \pm 371.4 \mathrm{ng} /$ $\mathrm{mL}$ indicative of passive smoking exposure ${ }^{31}$ while the exposed had significantly higher $(\mathrm{p}=0.049)$ measured urine cotinine levels of $747.8 \pm 502 \mathrm{ng} / \mathrm{mL}$ than the control group. Measured workplace PM2.5 levels among the controls' workplaces averaged from $0.01 \mathrm{mg} / \mathrm{m} 3$ to a maximum of $0.02 \mathrm{mg} / \mathrm{m} 3$. In contrast, an average PM2.5 level measured in the exposed groups' workplaces ranged from $0.64 \pm 0.37 \mathrm{mg} / \mathrm{m} 3$ to as much as $2.22 \pm 1.34 \mathrm{mg} /$ $\mathrm{m} 3$ and an independent t-test confirmed these levels were

\section{Table 1: Summary statistics of sample population}

\begin{tabular}{|c|c|c|c|c|c|}
\hline \multirow[t]{2}{*}{ Variable } & \multirow[t]{2}{*}{ Modalities } & \multicolumn{2}{|c|}{ Control $(n-30)$} & \multicolumn{2}{|c|}{ Exposed (n - 30) } \\
\hline & & $\mathbf{N}$ & $\%$ & $\mathbf{N}$ & $\%$ \\
\hline \multirow[b]{2}{*}{ Gender } & Male & 16 & 53 & 22 & 73 \\
\hline & Female & 14 & 47 & 8 & 27 \\
\hline \multirow{4}{*}{ Education } & High school & 6 & 20 & 10 & 33 \\
\hline & University & 21 & 70 & 13 & 43 \\
\hline & Graduate & 2 & 7 & 0 & 0 \\
\hline & Other & 1 & 3 & 7 & 23 \\
\hline Age & Mean & \multicolumn{2}{|c|}{34.4 SD \pm 1.96} & \multicolumn{2}{|c|}{$29.7 \mathrm{SD} \pm 1.47$} \\
\hline BMI & Mean & \multicolumn{2}{|c|}{24.6} & \multicolumn{2}{|c|}{24.5} \\
\hline
\end{tabular}

Note: BMI, body mass index; $n$, number; SD \pm , Standard Deviation 
significantly higher $(\mathrm{p}$-value $<0.000)$ than the control groups' workplaces.

\section{Results of Lung function tests}

Results of baseline spirometry parameters showed no significant differences between groups and were within normal limits. For exercise test results (Table 2) $\mathrm{VO}_{2}$ and

Table 2: Comparison of ergospirometry between Control and Exposed

\begin{tabular}{|c|c|c|c|c|}
\hline $\begin{array}{l}\text { Ergospirometric } \\
\text { Parameters }\end{array}$ & $\begin{array}{l}\text { Time } \\
\text { Point }\end{array}$ & $\begin{array}{l}\text { Control } \\
(\mathbf{3 0})\end{array}$ & $\begin{array}{l}\text { Exposed } \\
(\mathbb{N} 30)\end{array}$ & $\begin{array}{l}\text { P value } \\
\text { (t test) }\end{array}$ \\
\hline $\mathrm{O}_{2}$ consumption & & Mean $\pm S D$ & Mean $\pm S D$ & \\
\hline \multicolumn{5}{|l|}{$\mathrm{VO}_{2}(\mathrm{~mL} / \mathrm{kg} / \mathrm{min})$} \\
\hline & AT & $79.3 \pm 17.3$ & $72.1 \pm 13.8$ & 0.078 \\
\hline & $\mathrm{VO}_{2 \max }$ & $110.6 \pm 15.3$ & $98.9 \pm 14.8$ & 0.004 \\
\hline & $\mathrm{RC}$ & $92.6 \pm 21.6$ & $80.9 \pm 15.2$ & 0.018 \\
\hline
\end{tabular}

$\mathrm{VO}_{2}(\mathrm{~mL} / \mathrm{min})$

$\begin{array}{llll}\text { AT } & 79.5 \pm 17.4 & 72.1 \pm 13.8 & 0.073 \\ \mathrm{VO}_{2 \max } & 110.7 \pm 15.3 & 98.9 \pm 14.8 & 0.004 \\ \text { RC } & 92.6 \pm 21.6 & 80.9 \pm 15.3 & 0.019\end{array}$

$\mathrm{VCO}_{2}(\mathrm{~mL} / \mathrm{min})$

$\begin{array}{llll}\text { AT } & 65.3 \pm 12.7 & 58.4 \pm 11.4 & 0.032 \\ \mathrm{VO}_{2 \max } & 110.2 \pm 13.5 & 96.2 \pm 15.2 & 0.000 \\ \mathrm{RC} & 86.2 \pm 22.6 & 72.8 \pm 15.2 & 0.010\end{array}$

METS

$\begin{array}{llll}\text { AT } & 79.3 \pm 17.3 & 71.9 \pm 13.8 & 0.073 \\ \text { VO }_{2 \max } & 110.7 \pm 15.3 & 98.8 \pm 14.6 & 0.003 \\ \text { RC } & 92.5 \pm 21.6 & 80.8 \pm 15.1 & 0.018\end{array}$

Cardiac

$\mathrm{VO}_{2} / \mathrm{HR}(\mathrm{mL} /$ beat $)$

$\begin{array}{llll}\text { AT } & 97.7 \pm 18.1 & 90.8 \pm 14.0 & 0.103 \\ \mathrm{VO}_{2 \max } & 122.8 \pm 38.4 & 106.2 \pm 15.3 & 0.032 \\ \text { RC } & 103.2 \pm 20.0 & 91.3 \pm 14.9 & \mathbf{0 . 0 1 1}\end{array}$

$\mathrm{V} / \mathrm{Q}$

$\mathrm{VE} / \mathrm{VO}_{2}$

AT $\quad 64.5 \pm 18.0 \quad 63.8 \pm 6.0 \quad 0.841$

$\begin{array}{llll}\mathrm{VO}_{2 \max } & 84.2 \pm 11.6 & 83.1 \pm 8.6 & 0.678\end{array}$

RC $\quad 74.1 \pm 16.4 \quad 71.8 \pm 10.7 \quad 0.522$

$\mathrm{VE} / \mathrm{VCO}_{2}$
METS against (\%) predicted values showed significant differences $(\mathrm{p}<0.05)$ between groups at point of $\mathrm{VO}_{2} \max$ and $\mathrm{RC}$. $\mathrm{VCO}_{2}$ also showed a significant difference between groups for $\mathrm{AT}, \mathrm{VO}_{2} \max$ and $\mathrm{RC}$ time points. Oxygen pulse $\left(\mathrm{VO}_{2} / \mathrm{HR}, \mathrm{mL} /\right.$ beat $)$ at $\mathrm{VO}_{2} \max$ in the exposed group exhibited significantly lower values against their (\%) predicted than the control group by $16.6 \%(\mathrm{p}=0.032)$ while the respective percentage difference at $\mathrm{RC}$ was $11.9 \%(\mathrm{p}=0.011)$ (Figure 1).V/Q parameters $\mathrm{VE} / \mathrm{VO}_{2}$ and $\mathrm{VE} / \mathrm{VCO}_{2}$ showed relatively similar means between control and exposed groups and t-tests confirmed there was no difference ( $\mathrm{p}$-values $>0.05$ ), as did the WorkAT and WorkMAX t-test results.

\section{DISCUSSION}

Our results indicated that ergospirometric parameters are affected by chronic occupational SHS exposure. We found that chronic exposure to SHS has a negative impact on $\mathrm{VO}_{2}$, $\mathrm{VCO}_{2}$, METS and $\mathrm{VO}_{2} / \mathrm{HR}$ at points of $\mathrm{VO}_{2} \max$ and RC. These findings indicated that non-smoking, otherwise healthy, workers exposed to SHS in the workplace show lower exercise performance from an average of $6.9 \%$ to $14 \%$ than workers not exposed to SHS. In addition, non-smoking status was confirmed by exhaled CO measurements, exposure to SHS confirmed by urine cotinine and workplace environmental pollution through PM2.5 concentrations.

Non-enforcement of smoking ban legislation in Greece leads to SHS exposure outside work that could explain urine cotinine levels found in the control group especially since their measured CO indicated they were in fact, non-smokers ${ }^{24}$. Although this could also be the case in the exposed group, the fact that they exhibited significantly higher levels of urine cotinine $(\mathrm{p}<0.05)$ and environmental PM2.5 $(\mathrm{p}<0.000)$ as well as significantly decreased exercise performance $(p<0.05)$ could be attributed to supplemental SHS exposure in their workplace.

Oxygen pulse is a reliable index for assessing heart function ${ }^{21,32}$. It depends on the volume of oxygen extracted by the peripheral tissues and is the volume of oxygen uptake by the pulmonary blood during the period of a heartbeat ${ }^{21}$. It is the product of stroke volume and arterial-mixed venous 02 difference $^{21}$. Therefore, a decrease in stroke volume, anemia and carboxyhemoglobinemia are factors that lead to a decrease in oxygen pulse $\mathrm{e}^{21}$. Since the current study population had no history of heart disease or anemia, the lower values recorded in the exposed group could be explained by the formation of carboxyhemoglobinemia through inhalation of $\mathrm{CO}$ present in the SHS mixture as it is the case with cigarette
Note: $\mathrm{N}$, number; $\mathrm{AT}$, anaerobic threshold; $\mathrm{RC}$, recovery; HR maximum heart rate; $\mathrm{min}$, minute. All values are against $(\%)^{\text {max }}$ predicted values. P-value threshold $<0.05$ by independent $t$-test and indicated in bold. 
Figure 1: Mean values $(+\mathrm{SE})$ of maximum oxygen uptake over heart rate $\left(\mathrm{VO}_{2} / \mathrm{HR}\right)$ expressed as $(\%)$ predicted values in Control and Exposed at points of anaerobic threshold ( $\mathrm{AT})$, maximum oxygen uptake $\left(\mathrm{VO}_{2 m a x}\right)$ and recovery $(\mathrm{RC})$

\section{(\%) predicted}

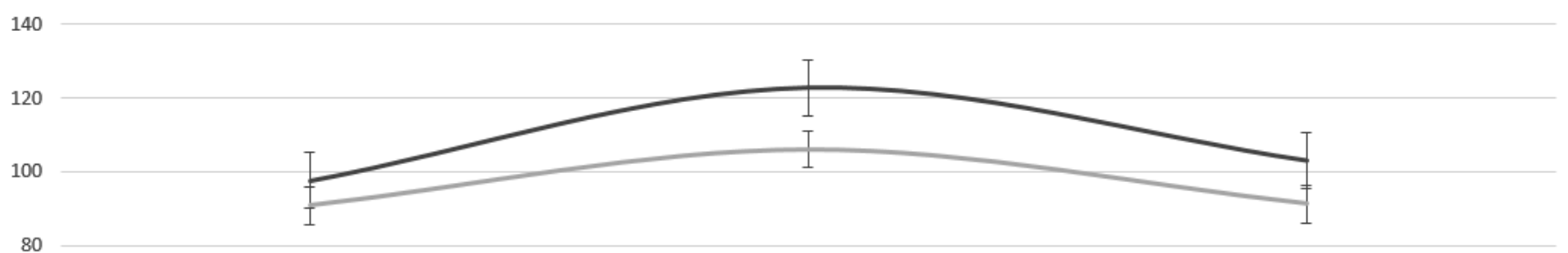

60

40

20

0

VO2MAX

$\mathrm{RC}$

smoking. Carboxyhemoglobinemia causes a leftward shift in the oxyhemoglobin dissociation curve, making it more difficult for oxygen to dissociate from hemoglobin $(\mathrm{Hb})$ at any given partial pressure of oxygen (PO2). Capillary PO2 then falls rapidly to its critical value and lactic acidosis occurs at a reduced level of Work reducing peak $\mathrm{VO}_{2}$ and $\mathrm{AT}$ and consequently adversely affecting exercise tolerance ${ }^{21}$.

Earlier studies that examined SHS exposure and exercise performance are in agreement with this study's findings although McMurray et al. and Flouris et al. studied the shortterm exposure effect of SHS while Their de Borba studied the effect in the general population whereas the current study measured the long-term occupational exposure to SHS. McMurray et al. examined short-term exposure to SHS and found that involuntary inhalation of SHS lowers maximal exercise capacity and submaximal response among smokers and non-smokers ${ }^{12}$ while Flouris et al. reported that a single hour of exposure to SHS adversely effects $\mathrm{VO}_{2} \max$ in healthy non-smokers ${ }^{33}$. Thier de Borba et al. also found that longterm SHS exposure affects $\mathrm{VO}_{2}$ max in the general population as it was significantly lower in passive non-smokers than in non-exposed non-smokers and very interestingly found no significant differences in $\mathrm{VO}_{2}$ max between smokers and passively exposed non-smokers ${ }^{13}$.

In regards to spirometry, normal flow-volume loops were found with no significant differences between groups. In contrast to these findings, Arjmandi et al. who examined healthy flight attendants found significant decreases in spirometric parameters (mid- and end- expiratory flow), diffusion capacity and lung volumes ${ }^{6}$. Their findings can be attributed to the significantly different environment represented by the flying aircraft cabin, where changes in altitude, pressure fluctuations as well as exposure to ozone, $\mathrm{CO} 2$ and various other pollutants (fungi, bacteria, protozoa) exert physical strain on a traveler's body $^{34}$. While partial pressure of oxygen in the atmosphere remains at $21 \%$, the atmospheric pressure in the air cabin drops at high altitudes and results in lower partial pressure of oxygen $^{35}$ and the consequent hypobaric hypoxia could be the underlying mechanism for decreased diffusion found in their study. Air trapping could also be explained by Boyle's law; as pressure falls in the air cabin while temperature remains constant the volume of gas in the bodies' cavities increases ${ }^{36}$.

Although the control group was not exposed to SHS in the workplace (PM2.5 measurements $<0.024 \mathrm{mg} / \mathrm{m} 3)^{31}$ and exhaled CO indicated non-smoker levels ${ }^{24}$, urine cotinine levels can only be explained by SHS exposure in daily activities other than at work. Wendy Max et al., found that despite many years of tough tobacco-control policies in California, people continue to be exposed to SHS at home and in the workplace ${ }^{16}$.

PM2.5 has been established as a hazard in the environment linked to CVD and increased mortality risk ${ }^{37}$. According to Haberzzetl et al., PM2.5 induces CVD through decreasing 
antioxidant capacity of the lung ${ }^{38}$. Therefore, enhancing the antioxidant defense in the lungs could reduce risk of CV injury associated with PM2.5 exposure ${ }^{38}$. Cigarettes emit high levels of PM2.5 when smoked ${ }^{39}$. Results of the current study showed the exposed group were at times exposed to substantial amounts of PM2.5 in the workplace and also confirmed failure of smoking ban enforcement in bars and cafes in Greece, while control workplaces had very low PM2.5 readings. These findings are supported by Wortley et al., who found that SHS exposure varies with occupation; with blue collar and service workers exhibiting higher and white collar workers lower levels of exposure ${ }^{40}$. High SHS exposure has also been found among casino workers ${ }^{8}$.

SHS increases the risk of lung cancer and coronary heart disease by up to $30 \%{ }^{41}$. Repeated studies at cellular level and among animals have shown that exposure even at the lowest levels of SHS increase the risk on the CV system ${ }^{11}$. Other studies have shown that exposure to SHS before 25 years of age have higher risk of developing lung cancer than those exposed after $25^{41}$. Smoking bans have been proven to be associated with reduced coronary episodes ${ }^{11}$. Raitakari et al. found that endothelial function, a marker of arterial health, was significantly better in young adults who had withdrawn from regular exposure to environmental tobacco smoke than in passive smokers ${ }^{42}$. However, the evidence of respiratory health impact of indoor smoking bans is not as robust ${ }^{9}$ and findings of the current study support the enforcement of bans to improve respiratory performance of non-smokers which could have a substantial impact on prevalence of disease, quality of life and consequently an economic gain ${ }^{37}$.

When particular workplaces such as hospitality venues are exempt from implementing the smoking ban legislation, it provokes discrimination against workers; offering health protection to those who work in smoke-free workspaces while those exempt from the law are left unprotected and at risk for serious chronic diseases while their basic human ${ }^{43}$ and labor rights are violated ${ }^{44-46}$. Article 7 of the International Covenant on Economic, Social and Cultural rights ${ }^{44}$ and the Lisbon treaty ${ }^{45}$ state that all working individuals must be protected from harm and enjoy safe and healthy work environments while Article 8 of the WHO Framework Convention for Tobacco control specifically outlines protection from $\mathrm{SHS}^{46}$.

It is acknowledged that repeated studies are needed to assume any generalizability due to the current study's limited sample size. Uneven distribution of gender in the exposed group was also a limitation, seemingly caused by more men being employed in the hospitality industry in Greece than women. PM2.5 levels in workplaces were limited to reflect momentary exposure in the workplace and hence may not be directly associated with recent exposure to SHS.

\section{CONCLUSION}

Among healthy adult non-smokers, chronic SHS exposure of those who worked in hospitality venues contributed to lower exercise performance. Its impact on chronic disease development should be further explored. These results add to the evidence of the importance of enforcing clean indoor air legislations and protecting nonsmokers from exposure to SHS.

\section{REFERENCES}

1. Hirayama T. Non-smoking wives of heavy smokers have a higher risk of lung cancer: a study from Japan. Br Med J (Clin Res Ed). 1981;282(6259):183-5.

doi:10.1136/bmj.283.6296.915

2. Trichopoulos D, Kalandidi A, Sparros L MB. Lung cancer and passive smoking. Int J Cancer. 1981;27(1):1-4.

doi: 10.1002/ijc.2910270102

3. European Lung white book. Passive smoking - ERS [Internet]. Available from: http://www.erswhitebook.org/chapters/passivesmoking/ (accessed November 2016)

4. Kobayashi Y, Takeuchi T, Hosoi T, Loeppky JA. Effects of habitual smoking on cardiorespiratory responses to sub-maximal exercise. J Physiol Anthropol Appl Human Sci [Internet]. 2004 Sep;23(5):163-9. doi: 10.1186/2049-6958-9-34

5. ASH. ASH research report: The health effects of exposure to secondhand smoke [Internet]. 2014. Available from: http://ash.org. uk/files/documents/ASH_597.pdf (accessed November 2016)

6. Arjomandi M, Haight T, Redberg R, Gold WM. Pulmonary function abnormalities in never-smoking flight attendants exposed to secondhand tobacco smoke in the aircraft cabin. J Occup Environ Med [Internet]. NIH Public Access; 2009 Jun;51(6):639-46. doi: 10.1097/JOM.0b013e3181a7f048

7. Flouris AD, Koutedakis Y. Immediate and short-term consequences of secondhand smoke exposure on the respiratory system. Curr Opin Pulm Med. 2011;17(2):110-5. doi:10.1097/MCP.0b013e328343165d

8. Pilkington PA, Gray S, Gilmore AB, Daykin N. Attitudes towards second hand smoke amongst a highly exposed workforce: Survey of London casino workers. J Public Health (Bangkok). 2006;28(2):104-10.

doi:10.1093/pubmed/fdi086

9. Frazer K, Callinan JE, McHugh J, van Baarsel S, Clarke A, Doherty $\mathrm{K}$, et al. Legislative smoking bans for reducing harms from secondhand smoke exposure, smoking prevalence and tobacco consumption. In: Frazer K, editor. Cochrane Database of Systematic Reviews [Internet]. Chichester, UK: John Wiley \& Sons, Ltd; 2016. doi:10.1002/14651858.CD005992.pub3

10. ITC Project, World Health Organization, and World Heart Federation. Cardiovascular harms from tobacco use and secondhand smoke: Global gaps in awareness and implications for action [Internet]. Waterloo, Ontario, Canada and Geneva, Switzerland; 2012. Available from: http://apps.who.int/iris/bitst ream/10665/85383/1/9789241505253_eng.pdf?ua=1 (accessed April 2016)

11. Institute of Medicine. Secondhand Smoke Exposure and Cardiovascular Effects: Making Sense of the Evidence. Institute of Medicine. 2009. 
12. McMurray RG, Hicks LL, Thompson DL. The effects of passive inhalation of cigarette smoke on exercise performance. Eur J Appl Physiol Occup Physiol. 1985;54(2):196-200. doi:10.1007/BF02335929

13. Thier de Borba AT, Jost RT, Gass R, Nedel FB, Cardoso DM, Pohl $\mathrm{HH}$, et al. The influence of active and passive smoking on the cardiorespiratory fitness of adults. Multidiscip Respir Med [Internet]. 2014;9(1):34. doi: 10.1186/2049-6958-9-34

14. American Cancer Society and World Lung Foundation. Smoke-free Policies | The Tobacco Atlas [Internet]. Available from: http://www. tobaccoatlas.org/topic/smoke-free-policies/ (accessed November 2016)

15. Vardavas CI, Anagnostopoulos N, Patelarou E, Minas M, Nakou C, Dramba V, et al. Five-Year Trends of Second-Hand Smoke Exposure in Greece: A Comparison Between Complete, Partial, and Prelegislation Levels. J Aerosol Med Pulm Drug Deliv [Internet]. Mary Ann Liebert, Inc. 140 Huguenot Street, 3rd Floor New Rochelle, NY 10801 USA ; 2012 Dec;25(6):349-54. doi:10.1089/jamp.2011.0949

16. Max W, Sung H-Y, Shi Y. Exposure to secondhand smoke at home and at work in California. Public Health Rep [Internet]. 2012;127(1):81-8.

17. Kharitonov SA, Yates D, Barnes PJ. Increased nitric oxide in exhaled air of normal human subjects with upper respiratory tract infections. Eur Respir J. 1995;8(2):295-7. doi:10.1183/09031936.95.08020295

18. American Thoracic Society. American Thoracic Society - Pulmonary Function Testing [Internet]. 2016. Available from: https://www. thoracic.org/statements/pulmonary-function.php

19. Miller MR, Hankinson J, Brusasco V, Burgos F, Casaburi R, Coates A, et al. Standardisation of spirometry. doi: 10.1183/09031936.05.00034805

20. Araujo CGS, Stein R, Serra SM H. AH: Teste cardiopulmonar de exercício. Arq Bras Cardiol. 2010;95(5):1-26.

21. Wasserman K, Hansen JE, Sue DY, Casaburi R, Whipp BJ. Principles of Exercise Testing and Interpretation 3rd Edition [Internet]. 3rd ed. Baltimore: Lippincott Williams \& Wilkins; 1999. 1-556 p. Available from: http://am-medicine.com/2016/05/principles-exercisetesting-interpretation-5th-edition-pdf.html (accessed November 2016)

22. Harris JA, Benedict FG. A biometric study of human basal metabolism. 1918; doi:10.1073/pnas.4.12.370

23. Bedfont Scientific Ltd. - Smokerlyzer [Internet]. Available from: http://www.bedfont.com/shop/smokerlyzer (accessed November 2016)

24. Deveci SE, Deveci F, Açik Y, Ozan AT. The measurement of exhaled carbon monoxide in healthy smokers and non-smokers. Respir Med [Internet]. 2004 Jun;98(6):551-6. doi: 10.1016/j.rmed.2003.11.018

25. Marbury MC, Hammond SK, Haley NJ. Measuring exposure to environmental tobacco smoke in studies of acute health effects. Am J Epidemiol [Internet]. 1993 May 15;137(10):1089-97. Available from: http://www.ncbi.nlm.nih.gov/pubmed/8317438 (accessed November 2016)

26. Benowitz NL, Hukkanen J, Jacob P. Nicotine Chemistry, Metabolism, Kinetics and Biomarkers. In: Nicotine Psychopharmacology [Internet]. Berlin, Heidelberg: Springer Berlin Heidelberg; 2009. p. $29-60$. doi:10.1007/978-3-540-69248-5_2

27. Avila-Tang E, Al-Delaimy WK, Ashley DL, Benowitz N, Bernert JT, Kim S, et al. Assessing secondhand smoke using biological markers. Tob Control [Internet]. BMJ Publishing Group Ltd; 2013 May;22(3):164-71.

doi:10.1136/tobaccocontrol-2011-050298

28. Benowitz NL. Cotinine as a biomarker of environmental tobacco smoke exposure. Epidemiol Rev 18. 1996;18(2):188-204. doi: 10.1093/oxfordjournals.epirev.a017925

29. DRG Diagnostics GmbH | DRG ELISAs [Internet]. Available from:http://www.drg-diagnostics.de/44-1-DRG+ELISAs. html?ItemPage=1 (accessed November 2016)

30. New York State Department of Health. Fine Particles (PM 2.5) Questions and Answers [Internet]. 2011. Available from: https:// www.health.ny.gov/environmental/indoors/air/pmq_a.htm (accessed November 2016)

31. Behera D, Uppal R, Majumdar S. Urinary levels of nicotine \&amp; cotinine in tobacco users. Indian J Med Res. 2003;

32. Firstbeat technologies. VO 2 Estimation Method Based on Heart Rate Measurement. 2012. Available from: https://www.firstbeat. com/app/uploads/2015/10/white_paper_vo2_estimation.pdf (accessed November 2016)

33. Flouris AD, Metsios GS, Carrill AE, Jamurtas AZ, Stivaktakis PD, Tzatzarakis MN, et al. Respiratory and immune response to maximal physical exertion following exposure to secondhand smoke in healthy adults. PLoS One [Internet]. 2012;7(2):2-9. doi 10.1371/journal.pone.0031880

34. Airliner T, Environment C, Quality A, Committee S, Cabin A, Quality A, et al. The Airliner Cabin Environment. 1986.

35. Chandra A, Conry S. In-flight Medical Emergencies. West J Emerg Med [Internet]. 2013;14(5):499-504.

doi:10.5811/westjem.2013.4.16052

36. Ahmedzai S, Balfour-Lynn IM, Bewick T, Buchdahl R, Coker RK, Cummin AR, et al. Managing passengers with stable respiratory disease planning air travel: British Thoracic Society recommendations. Thorax [Internet]. 2011 Sep 1;66(Suppl 1):i1-30. doi:10.1136/thoraxjnl-2011-200295

37. Wilson N, Edwards R, Parry R. A persisting secondhand smoke hazard in urban public places: Results from fine particulate (PM2.5) air sampling. N Z Med J. 2011;124(1330).

38. Haberzettl P, McCracken J, Folz R, Zelko I, Bhatnagar A, Conklin DJ. Abstract 16056: Pulmonary Oxidative Stress Contributes to Ambient Fine Particulate Matter (PM2.5)-Induced Vascular VEGF Resistance and Endothelial Progenitor Cell Retention. Circulation. 2014;130(Suppl 2).

39. Gerber A, Hofen-Hohloch A V, Schulze J, Groneberg DA, Brunekreef $\mathrm{B}$, Holgate S, et al. Tobacco smoke particles and indoor air quality (ToPIQ-II) - a modified study protocol and first results. J Occup Med Toxicol [Internet]. BioMed Central; 2015 Dec 15;10(1):5. doi: 10.1186/s12995-015-0047-8

40. Wortley PM, Caraballo RS, Pederson LL, Pechacek TF. Exposure to secondhand smoke in the workplace: serum cotinine by occupation. J Occup Environ Med [Internet]. 2002;44(6):503-9. doi: 10.1097/00043764-200206000-00010

41. Asomaning K, Miller DP, Liu G, Wain JC, Lynch TJ, Su L, et al. Second hand smoke, age of exposure and lung cancer risk. Lung Cancer. 2008;61(1):13-20.

doi: 10.1016/j.lungcan.2007.11.013

42. Raitakari OT, Adams MR, McCredie RJ, Griffiths KA, Celemajer DS. Arterial Endothelial Dysfunction Related to passive Smoking 


\section{Research Paper}

is Potentially Reverible in Healthy Young Adults. Ann Intern Med. 1999;130(7):578-81.

43. United Nations General Assembly. Universal Declaration of Human Rights. 1948 p. 1-8.

44. International Covenant on Economic, Social and Cultural Rights. English 1966 p. 1-4.

45. TreatyofLisbon[Internet].2007.Availablefrom:http://eur-lex.europa. eu/legal-content/en/TXT/?uri=CELEX\%3A12007L\%2FTXT (accessed November 2016)

46. World Health Organization. WHO Framework Convention on Tobacco Control [Internet]. Geneva; 2007. Available from: http:// www.who.int/tobacco/framework/WHO_FCTG_english.pdf (accessed November 2016)

CONFLICT OF INTERESTS Author PKB is the Editor-in-Chief of Tobacco Prevention \& Cessation. All the authors have completed and submitted the ICMJE Form for Disclosure of Potential Conflicts of Interest and none were reported.

FUNDING

This work was supported by The Behrakis Foundation, Boston MA.

PROVENANCE AND PEER REVIEW

Commissioned,

Externally peer reviewed 